\title{
Gastroscopic Findings and Fecal Blood Loss Following Aspirin Administration
}

\author{
Donald H. Kuiper, MD, Bfrgein F. Overholt, MD, \\ Daniel J. Fall, MD, and H. Marvin Pollard, MD
}

\begin{abstract}
A study of 19 healthy young male subjects (Group, 1) was made in which a correlation of aspirin ingestion, fecal blood loss, blood salicylate levels. prothrombin concentrations, and ABO blood groups was sought. An initial d-day control period was followed by a 4-day test period during which subjects ingested $650 \mathrm{mg}$ aspirin with each meal and at bedtime. Gastroscopy with photography was done on Day 1 and Day 7 . Daily fecal blood loss was quantitated .using the 5l-chromium tagged erythrocyte method. Sixteen patients (Group 2) with a variety of upper gastrointestinal disorders underwent gastroscopy and photography before and after the acute ingestion of aspirin. Results reveal: (1) Aspirin produced petechiae in 4 of 18 subjects and a hemorrhagic gastrit is in 1 of 18 in Group 1, (2) aspirin produced no visible lesions in the 16 subjects in Group 2, (3) the mean fecal blood loss during the control period was $0.38 \pm 0.35 \mathrm{~g} / 24 \mathrm{hr}$ and rose to $1.54 \pm 1.42 \mathrm{~g} /$ $24 \mathrm{hr}(\mathrm{p}<0.01)$ during aspirin ingestion, (4) no correlation between normal or abnormal gastroscopic findings and fecal blood loss was apparent, and (5) no correlation between blood salicylate levels, prothrombin concentrations, and gastroscopic findings or fecal blood loss was detected.
\end{abstract}

$\mathrm{M}$ ANy sTudies have been carried out in both healthy volunteers and patients in order to define the effect of aspirin upon the human stomach. Endoscopic studies done following the ingestion of aspirin have provided conflicting results concerning the lesion induced by aspirin. ${ }^{1-\tau}$ These results have depended upon the variable experimental conditions and the patient's underlying illness. It is clear, however, that aspirin cloes increase the fecal blood loss in normal and abnormal subjects. ${ }^{\text {s-10 }}$

To our knowledge, no study has measured fecal blood loss in the same group of subjects who were evaluated by gastroscopy. It is the purpose of this communication to present the results of fecal blood loss and gastroscopic: findings in a group of healthy volunteers cluring a control period and after a period of aspirin ingestion. In addition, gastroscopic data are presented from

From the Department of Intemal Medicine, Division of Gastrocnterology, Lniversity of Michigan Medical Center, Ann Arbor. Mich.

Supported by grants from Bristol-Mvers Co., NY. NIH crant 1-T01-AM-05539-01, and the American Cancer Societr.

Address for reprint requests: Donald H. Kuiper. Mll. (iastoenterology Laboratory, Lintversity Medical Center, Ann Arbor. Mich $\$ 8104$.

* Present address: Scction of Gastroenterolog!. New rork Hospital Cornell Medical Center, New lork Cits. 
a group of patients with gastrointestinal disorders, following the acute ingestion of aspirin.

\section{METHODS}

\section{Grovp 1}

Nineteen healthy volunteers, ages 21-29 years, were studied in the Clinical Research Unit of our hospital. A history and physical examination were performed routinely. All subjects denied previous gastrointestinal disease or intolerance to aspirin. Following the base line studies (indicated at the bottom of Table 1), a gastroscopy with the Olympus GTF gastrocamera was performed $30 \mathrm{~min}$ after preparation using meperidine hydrochloride, $75-100$ $\mathrm{mg}$; atropine, $0.4 \mathrm{mg}$; pentobarbital, $100 \mathrm{mg}$; simethicone, 6 drops; and 2\% viscous lidocaine, topically. Two endoscopists independently examined each stomach. Appropriate photographs were taken of each stomach. Following the gastroscopy, $20.0 \mathrm{ml}$ of the patient's whole blood was mixed with $6.0 \mathrm{ml}$ acid citrate dextrose solution and was then incubated with $100 \mu \mathrm{c}$ of sodium chromate -51 at $37.0^{\circ} \mathrm{C}$ for $120 \mathrm{~min}$. Using this procedure, approximately $95 \%$ of the erythrocytes were tagged with the isotope. ${ }^{11}$ The tagged cells were then reinjected.

TABLE 1. CLINICAL DATA IN GROUP 1 SUBJECTS

\begin{tabular}{|c|c|c|c|c|c|}
\hline \multirow[b]{2}{*}{ Subject } & \multirow{2}{*}{$\begin{array}{l}\text { Bloor } \\
\text { group }\end{array}$} & \multirow[b]{2}{*}{ Age } & \multirow{2}{*}{$\begin{array}{c}\text { Post-aspirin } \\
\text { gastrosropy } \\
\text { findings }\end{array}$} & \multicolumn{2}{|c|}{ Mean fecal blood loss $(g / 2, h r)$} \\
\hline & & & & Control period & Test perind \\
\hline R.S. & A- & 22 & $\begin{array}{l}2 \text { petechiae lesser curve } \\
\text { antrum }\end{array}$ & $<0.2 .5$ & 0.83 \\
\hline S.H. & $\mathrm{O}-$ & $2 ; 3$ & $\begin{array}{l}3 \text { petechiae lesser curve } \\
\text { antrum }\end{array}$ & 0.48 & 2.40 \\
\hline T.G. & $A+$ & 22 & $\begin{array}{l}\text { Diffuse hemorrhagic } \\
\text { gastritis }\end{array}$ & 0.29 & 0.25 \\
\hline A.P. & $A+$ & 2.5 & $\begin{array}{l}1 \text { petechial hemorrhage } \\
\text { lesser curve antrum }\end{array}$ & 0.69 & 2.24 \\
\hline R.C. & $A+$ & 21 & $\begin{array}{l}\text { MIult petechiae greater } \\
\text { लाrve antrum }\end{array}$ & 0.30 & 0.78 \\
\hline C.I. & $\mathrm{O}+$ & 2.5 & Normal & 0.40 & 1.14 \\
\hline E.A. & $A+$ & 23 & Normal & $<0.25$ & 6.26 \\
\hline I.A. & $\mathrm{AB}+$ & 24 & Normal & 0.59 & 1.45 \\
\hline F.H. & $A+$ & 2.5 & Normal & 0.52 & 2.00 \\
\hline C.P. & $\mathrm{O}+$ & 2.5 & Normal & $<0.2 .7$ & 0.94 \\
\hline B.1). & $\mathrm{O}+$ & 23 & Normal & 0.74 & 1.57 \\
\hline B.C. & $\mathrm{AB}+$ & 24 & Normal & 0.40 & 2.03 \\
\hline R.T. & $A+$ & 24 & Normal & $<0.25$ & 0.46 \\
\hline MI.S. & $0+$ & 24 & Normal & 0.39 & 0.62 \\
\hline J.L. & $A+$ & 24 & Normal & $<0.2)$. & 1.01 \\
\hline I). $\mathrm{B}$. & $0+$ & 26 & Normal & $<0.25$ & 0.72 \\
\hline T.K. & B - & 26 & Normal & Hemolyzed & Hemolyzed \\
\hline I.C. & $A+$ & 2.5 & Normal & Fpistax is & Fpistaxis \\
\hline R. I.* & $A+$ & 29 & Normal & $<0.25$ & 0.45 \\
\hline
\end{tabular}

* Receired placebo. Baseline studies: Hematocrit. WBC. urine analysis, BUN, prothrombin time. 
Individual 24-hr fecal collections were made throughout the study, using tarred glass containers. All subjects were instructed to avoid urine contamination of the fecal collections. A 4-day control period was initiated on the day of admission. This was followed by a 4-day test period in which all subjects ingested $650 \mathrm{mg}$ of hospital-prepared aspirin* with each meal and at bedtime each day. All were fed a general diet and abstained from alcohol. Activity was not restricted. The only medication administered was Metamucil (psyllium hydrophilic mucilloid) +1 tablespoon, with 4 oz of water at 8 AMr and 5 PM daily in order to avoid constipation. On the morning of Day 7 (after 2 days of aspirin ingestion), each subject again underwent gastroscopy $30-45 \mathrm{~min}$ following the ingestion of $650 \mathrm{mg}$ aspirin on the fasting stomach. Prothrombin concentrations were again drawn on Day 3 of the test period. Daily blood salicylate levels were determined on each subject using the ferric chloride method. ${ }^{12}$

Employing the ashing technic, 24-hr stool samples were radio assayed. With this technic, $0.25 \mathrm{~g}$ of whole blood may be detected in a 24-hr stool with an error of less than $8 \%$ when stool samples are counted for $10 \mathrm{~min}$. An upper gastrointestinal X-ray with a small bowel follow-through, done the day following the test, was normal in all subjects.

\section{Group 2}

Sixteen patients with a variety of upper gastrointestinal disorders including gastric ulcer, gastric carcinoma, gastric mucosal atrophy, and marginal ulceration, underwent gastroscopy and photography shortly before and after aspirin ingestion. This was done after preparation as described in Group 1 except that $4 \%$ cocaine was employed as a topical anesthetic.

In Group 2A (10 patients), immediately following initial endoscopy and photography, the patients were given two 325-mg hospital-prepared aspirin tablets with 1-2 oz water. The patient was then instructed to lie on his back. A gastroscopy with photography was repeated $30 \mathrm{~min}$ later.

In Group 2B (6 patients), following the initial gastroscopy, two 325-mg aspirin tablets were administered with 1-2 oz water. Another $650 \mathrm{mg}$ dose was given $90 \mathrm{~min}$ later. Two hours after the first aspirin dose, gastroscopy and photography were again performed.

Gastric aspirations were not performed prior to endoscopy. Two examiners individually recorded their endoscopic impression. After processing, the photographs were coded and the photographic interpretation was compared with the recorded impression. No significant discrepancies occurred. A gastroscopy was considered abnormal when hemorrhage, petechiae, or ecchymoses were present. Erythema was not considered abnormal because this was an inconsistent finding from endoscopist to endoscopist.

*Acetylsalicylic acid, $325 \mathrm{mg}$, with $10 \%$ starch filler.

+Searle \& Company, Chicago, Ill. 


\section{RESULTS}

\section{Frati Bloon Loss}

Valid data were obtained in 17 of the 19 subjects studied in Group 1 (Table 1). In Subject I,K., hemolysis occurred, making estimation of fecal blood loss impossible. In all others, normal decay curves for chromium-51 werc obtained. One subject (L.C.) developed an episode of epistaxis on the last day of the control period, invalidating his fecal blood studies. Another subject (R.V.) was given a placebo during the test period. His data are listed on the bottom of Table 1. Two subjects (J.L. and D.B.) were given a charcoal marker to determine how rapidly the material from the stomach would be found in the feces. This appeared in the stool at 24 and $36 \mathrm{hr}$, respectively, after administration. At no time cluring the test period did any subject complain of distress. No gross blood was seen in any stool collection. Results of the fecal blood loss studies are shown in the graph (Fig 1). The

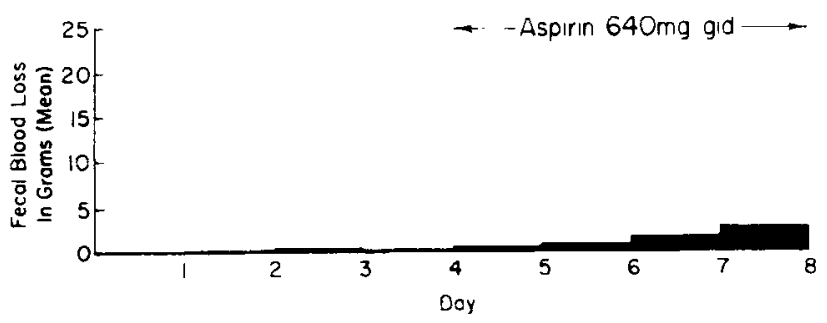

Fig 1. Daily mean fecal bleos loss in 16 momal subjects.

mean 24-he fecal blood loss during the control period was $0.38 \pm 0.35$ (1 SD) gr blood. However, during the period of aspirin administration, the 24-hr mean fecal blood loss rose to $1.54 \pm 1.42$ (1 SD) g blood. The mean fecal blood loss on Day 1 of the control period was less than $0.25 \mathrm{~g} / 2-1 \mathrm{~h}$ with a loss of $0.50 \mathrm{~g} /$ 21 hr on Day 3 of the control period. When Student's T-iest is applied to the data, this difference is significant $(\mathrm{P}=<0.01)$. We have no explanation for this increase, although it may have been due to gastroscopy. To test this hypothesis, 5 additional normal subjects were studied in the same manner excluding endoscopy. The results reveal a mean $21 \cdot \mathrm{hr}$ fecal blood loss during the control period of $0.32 \pm 0.02$ ( $1 \mathrm{SD}$ ) $\mathrm{g} / 2+\mathrm{hr}$ and a rise to $1.41 \pm 0.29$ (1 SD) $g / 2-4 h r$ during the test period. When the $T$-test is applied to the bloxl loss data of Day 3 for the group who had endoscopy and the group who did not have endoscopy, the difference is not significant $(\mathrm{p}=>0.40)$.

The mean fecal blood loss increases during the control period was significant $(\mathrm{p}=<0.01)$. If we exclude in our calculations, Subject E.A.. who bled the greatest amount, the mean increase in the fecal blood losi during the control period is still highly significant $(p=<0.01)$. 


\section{Gastrobcopic Stldies}

Group 1. Eighteen of the nineteen control gastroscopie, were interpreted as normal by the two endoscopists. The only subject (F.H.) whose control gastroscopy was compatible with a diffuse gastritis ingested a moderate amount of alcohol during the $24 \mathrm{hr}$ prior to admission. His gastroscopy following aspirin administration was completely normal. Subject J.L. ingested $40 \mathrm{~g}$ of aspirin for approximately I week for a "head cold" but had discontinued his aspirin intake $\&$ days prior to the initiation of this study. The endoscopic examination of his stomach was normal. Of the 19 subjects, 5 (R.S., S.H., T.C., A.P., and R.C.) showed abnormalities on the gastroscopic examination when compared with the control examination (Table 1). Of the 5, 4 had mucosal petechiae (Fig 2) and 1 had a diffuse hemorrhagic gastritis of the

Fig 2. Subject R.C., Post. aspirin vicw of gastric antrum with angulus and lesser curvature to right; $\mathbf{3}$ distinct petechiac are scen just left of angulus.

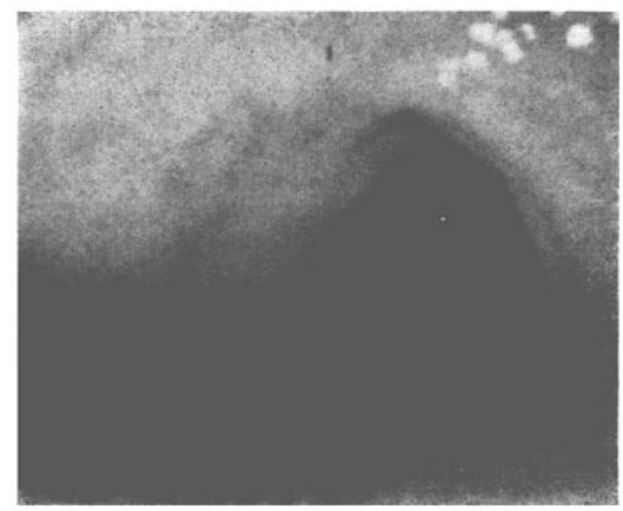

entire visualized stomach. This subject was the only one who showed gross bleeding. Of the four with petechiae, 3 had their lesions on the lesser curvature of the antrum; the other had petechiae on the greater curvature of the antrum. The other 14 subjects had compleely normal gastroscopies. Aspirin particles adherent to the mucosa or the mucous lakes were frequently seen. When these particles were identified we were unable to demonstrate abnormality of the mucosa surrounding the adherent particles.

Group 2A. One subject demonstrated hyperemic changes 1-2 $\mathrm{mm}$ in diamcter on the lesser curvature of the gastric antrum, but no bleeding points or mucosal crosions were found. In all the subjects of this group, it was possible to demonstrate particles of aspirin dissolved in the mucous lake or small to medium particles of aspirin adhering tenaciously to the mucosa. Occasionally a partially dissolved tablet lying against the gastric mucosa was seen, but it was not possible to demonstrate any hyperemia, hemomhage, or erosions either immediately adjacent to the aspirin particles or elsewhere in the stomach.

Group 2B. Of the 6 patients, 2 showed slight hyperemia near the flecks of 
aspirin in the nucusa. Igain it was not possible to find hemorrlages or mucosal erosions in the stomach.

\section{Blood Salicylate Levels}

Of the 19 subjects in Group I, 18 had daily blood salicylate level determinations. In all cases, the blood level was measured about $8 \mathrm{hr}$ after administration of the last $650 \mathrm{mg}$ aspirin dose. The blood salicylate levels ranged from 2.4 to $10.8 \mathrm{mg} / 100 \mathrm{ml}$. In those 5 subjects who showed abnormalities at gastroscopy, the blood salicylate level ranged from $3.0 \mathrm{mg}$ to $8.2 \mathrm{mg} / 100 \mathrm{ml}$.

\section{BLOOD GRoups}

In Group 1 the ABO blood group distribution consisted of:

\begin{tabular}{cccc}
$\begin{array}{c}\text { Blood } \\
\text { group }\end{array}$ & Yo. & $\begin{array}{c}\text { Distribution } \\
\left(\mathrm{C}^{\circ}\right)\end{array}$ & $\begin{array}{c}\text { Expected } \\
\text { distribution } \\
(\%)\end{array}$ \\
\hline A & 10 & 52.6 & 39.2 \\
O & 6 & 31.5 & 42.2 \\
AB & 2 & 10.5 & $13.5)$ \\
B & 1 & 5.2 & .5 .1
\end{tabular}

Of the 5 subjects with gastroscopic abnormalities, 4 were of blood Group A, the other had blood Group $O$. Because our population was weighed with subjects in blood Group $A$, we were unable to find a valid correlation between the magnitude of fecal blood loss and a single blood group.

\section{Prothrombin Concentration}

All the subjects in Group 1 had control prothrombin level determinations. Of the 19,9 had prothrombin determinations during the. test. No significant change of the prothrombin concentration was found during the test period.

\section{DISCUSSION}

\section{Gastroscopic Studies Following Aspikin Administration}

Multiple gastroscopic studies following aspirin therapy have been performed. Due to the variations in experimental design and individual interpretation of the underlying disease process involving the stomach, the results are often conflicting. Douthwaite and Lintott ${ }^{1}$ reported that 13 out of 16 patients revealed abnormalities consisting of slight hyperemia to submucosal hemorrhage following the ingestion of $15 \mathrm{~g}$ of crushed aspirin. However, they did not perform control gastroscopies and they aspirated the stomach prior to gastroscopy. Our experience indicates that vigorous aspiration prior to 
gastroscopy may produce submucosal hemorrhage. Weiss et alı performed control gastroscopies but included an aspiration as part of their preparation. They found abnormalities in 13 out of 30 patients studied within 15 min of the administration of $15 \mathrm{~g}$ aspirin. Caravati and Cosgrove ${ }^{3}$ studied the effect of oral aspirin and intravenous sodium salicylate on 20 patients. With blood levels of $30 \mathrm{mg} / 100 \mathrm{ml}$, only 1 patient showed a superficial gastritis. With a gastroscope in place, Vickers administered $650 \mathrm{mg}$ aspirin/tube to 70 patients and observed the effects for up to $35 \mathrm{~min}$; he found lesions in 12 patients. Whether or not a pre-endoscopic aspiration was performed on his patients is unclear.

Thorsen $e t$ al ${ }^{5}$ using the gastrocamera, administered $600 \mathrm{mg}$ of aspirin to a group of healthy volunteers and varied the $\mathrm{pH}$ of the gastric contents. They showed that the abnormality seen at gastroscopy was related to the low intragastric $\mathrm{pH}$. However, these authors had aspirated the stomach prior to endoscopic examination.

The lesions reported by these authors have been described as varying from small petechial hemorrhages to frank erosive and hemorrhagic gastritis occurring primarily along the lesser curvature of the antrum. In contrast, however, are the reports of $\mathrm{Paul}^{6}$ and $\mathrm{Rider}^{7}$ who found no endoscopic evidence incriminating aspirin as a cause of such lesions.

In our Group 1 subjects, 5 of 19 revealed abnormalities which we attribute to the aspirin ingestion. In the Group 2 subjects, there were no abnormalities which we could attribute to the aspirin. Although Groups 1 and 2 are not comparable, the presence of pre-existing disease within the stomach did not seem to influence the occurrence of visible lesion.

In many of our subjects, the aspirin could be seen as an incompletely dissolved tablet or as large or small flecks adhering to the mucosa. No surrounding abnormality was observed except in the patient who demonstrated hemorrhagic gastritis. However, this does not rule out lesions underneath the aspirin as it could not be "wiped away" with the scope. Our study is somewhat limited because of the limitations of the GTF gastrocamera which do not permit good visualization of the gastric fundus. But all previous reports indicate that the lesions occur on the lesser curve of the antrum, and frequently lesions are scattered throughout the gastric mucosa.5 Furthermore, where the gastrocamera was used to visualize the cardia of the stomach, ecchymoses were disregarded in this area because they were attributed to instrument trauma. 5

\section{Fecal Blood Loss following Aspirin Administration}

Our control fecal blood loss values of $0.38 \pm 0.35 \mathrm{~g} / 24 \mathrm{hr}(1 \mathrm{SD})$ are in agreement with those of other authors who used the chromium-51 method. Our data are given in grams of blood lost. Wintrobe ${ }^{13}$ states that the specific gravity of normal blood ranges from 1.048 to 1.066 . Converting our weights 
to volume, our blood loss levels are slightly lower than those of others. Holt found $0.41 \mathrm{ml}$ blood in the $24-\mathrm{hr}$ stool in 10 normal volunteers. Croft and Wood, ${ }^{14}$ in studying 226 subjects with no known gastrointestinal disease, found a mean blood loss of $0.6 \mathrm{ml} / 24 \mathrm{hr}$. Pierson ${ }^{10}$ found a mean $24-\mathrm{hr}$ fecal blood loss in normal people of $0.5 \mathrm{ml}$ for $24 \mathrm{hr}$, and Bouchier and 1 ivilliams ${ }^{15}$ found a 2.4-hr mean loss of $0.36 \mathrm{ml}$ in healthy subjects.

During the period of aspirin administration, we found a mean lecal blood loss of $1.54 \mathrm{~g} / 2+\mathrm{hr}$. Pierson et al ${ }^{\mathrm{s} 0}$ found $4.7 \pm+.1 \mathrm{ml}$ fecal blood loss during administration of $600 \mathrm{mg}$ of aspirin four times daily. Holt $\mathrm{t}^{6}$ found a mean 24-hr fecal blood loss of $5.72 \mathrm{ml}$ during the oral administration of $600 \mathrm{mg}$ of aspirin four times daily for 6 clays to healthy volunteers. Our lower values might be due to the fact that we assayed feces during a 4-day period of aspirin administration while these authors administered aspirin for 6 days and initiated fecal collections on Day 4 of drug administration. It is probable that collection of the stool after the blood loss had been established for several days accounted for the difference, as we collected our specimens during the establishment of blood loss.

Although visible gastroscopic abnormalities were noted in only 5 of 19 subjects in Group I, this does not rule out the possibility that gastric mucosal lesions were present at other points in time, since gastroscopy and gastrophotography view the stomach for a brief finite period of time. If indeed, one could say with certainty that all stomachs were unremarkable at all times during the test period, one might speculate that perhaps the fecal blood loss originated elsewhere in the gastrointestinal tract. The stomach may not be the source of the blecling but additional work is needed to answer this question.

No correlation between the changes in prothrombin concentration or blood salicylate levels and lecal blood loss wats found.

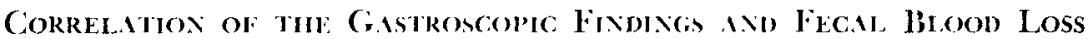

Subjects R.S., S.H., 'T.C... A.P., and R.C. Clemonstrated abnormalities on cndoscopic examination. The, lost respectively $0.83,2.42,0.17,2.24$, and 0.78 in of blood during the aspinin-ingestion period. These values fall well within one standard deviation of ow mean fecal blood loss and are equal to or below the greatest blood loss levels that were found in subjects E..A., B.G., and F.H., who had normal gastroscopic findings. It thus appears that under the conditions of our study, the increased fecal blood loss following aspirin therapy is not correlated with grossly visible gastric lesioms.

\section{REFERENCILS}

1. Dourmwate, A. G., and Lisotr, G. S. M. Gastroscopic obsendations of the eflect of aspirin and certain other substances on the stomach. Lancet 2:1222. 1938.

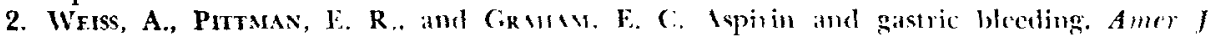
Med $31: 266,1961$. 
3. Caravat, C. M., and Comomi. E. F. Salicylate tosicil: The probalble mechanism of its action. Ann Intern Med 24:638, 1946.

4. Vickers, N. F. Mucosal effects of aspirin and acetaminophen: Report of a controlled gastroscopic study. Bull Gastroint Endosc 11:94. 1967.

5. Thorsex, W. B.. Westrex, D., TAxtke, Y., and Morrluger, J. F. Ispirin injury to the gastric mucosa. Awh Intern Med 121:409. 1968.

6. Pacl, W. D. The effect of acethalicylic acid (aspirin) on the gastric mucosa. J Iouta Med Soc 33:155, 1943.

7. Rider, J. A., Mofilir. H. C., and Pthili, J. The cllect of salicylates on the gastric mucosa. Bull Gastic Endosc s:5, 1962.

8. Grossman, M. I., Matscyoto. K. K., and Licher, R. I. Fecal blood loss produced by oral and intravenous administration of various salicylates. Gastroenterology 40:383, 1961.

9. Holt, P. R. Gastrointestinal blood loss in subjects taking aspirin. J Lab Clin Med $56: 717,1960$.

10. Pierson, R. M., Holt, P. R., Wisox, R. M., and heiting, R. P. Aspirin and gastrointestinal bleeding. Amer J Med $31: 25 \% 1961$

11. Gray, S. J., and STrRting, $K$. The tagging of red cells and plasma proteins with radioactive chromium. J Clin Iniest 29:1604. 1950.

12. Trinder, P. Rapid determination of salicylates in biologic fluids. Biochem $J$ 57:301, 1954.

13. Wintrobe, M. M. Clinical Hematology (ed. 6), Lea, Philadelphia, 1967, p. 352.

14. Crof T, D. N. and Woov, P. N. H. Gastric mucosa and susceptibility to occult gastrointestinal bleeding caused by aspirin. Brit Med I 1:1:37, 19ti7.

15. Bovchifr, I. A. D., and Wilinss, H. S. Determination of fecal blood loss after combined alcohol and solium acetslsalicilate intake. Lamcet $7: 178,1969$. 